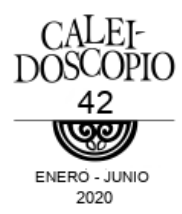

\title{
Una nueva concepción del arte y del artista en el arte contemporáneo
}

A new conception of art and artist in contemporary art

PATRICIA AURORA ORTIZ LOZANO

Universidad de las Artes, México

\section{RESUMEN}

Este artículo pretende mostrar cómo el artista pop Andy Warhol introduce una nueva concepción del arte y del artista. El nuevo modelo del artista que encarnó Warhol es transversal: se mueve entre la cultura de masas y el arte culto y utiliza diferentes disciplinas más allá de la pintura, como el diseño y la publicidad. Este artículo también muestra las diferencias entre Warhol y Duchamp y señala que éste último hace su ruptura (del mismo modo que los vanguardistas como él), dentro del modelo del arte moderno, cuya tradición era siempre rupturista. En Warhol no existe el espíritu de confrontación, por el contrario, el norteamericano se habitúa a la sociedad del espectáculo. Warhol no rompe con la pintura, como Duchamp lo hizo (dentro del relato legitimador del arte moderno a que se refiere Danto), sino que, todo lo toma y todo lo integra. De ahí su transversalidad como artista.

Palabras clave: Warhol; arte pop; Duchamp; arte; artista. 


\section{ABSTRACT}

This article aims to show how pop artist Andy Warhol introduces a new conception of art and artist. The new model of the artist that Warhol incarnated is transversal: he dwells between mass culture and elite art and uses different disciplines beyond painting, such as design and advertising. This article also shows the differences between Warhol and Duchamp and points out how he makes his rupture (in the same way as avant-garde artists like him), within the model of modern art, whose tradition was always disruptive. In Warhol there is no spirit of confrontation, on the contrary, the american artist is accustomed to the society of the spectacle. Warhol does not break with painting, as Duchamp did (within the legitimizing tale of modern art to which Danto refers); on the contrary, he takes and integrates everything. That is his transversality as an artist.

Keywords: Warhol; pop art; Duchamp; art; artist.

Andy Warhol cambió la forma de ver el arte, acortó la distancia entre el arte y la vida, hasta volverla imperceptible en ocasiones.

Warhol introduce una dimensión del artista como un creador transversal, es decir, que más allá de la pintura, se mueve entre diferentes técnicas, medios y procedimientos expresivos, como el diseño, la publicidad y el cine. El norteamericano llegó a utilizar incluso su propia personalidad para configurar la nueva concepción del artista contemporáneo. 
Warhol pisa la escena del arte y el Pop encuentra a su máxima estrella. Fue pintor, dibujante, artista gráfico, director de cine, publicista y promotor de talentos, y tuvo el valor de reconocer en la sopa Campbell's y la Coca- Cola el denominador común que aglutina a apocalípticos e integrados. Liberales y conservadores [...] El arsenal que nutre sus propuestas se encuentra por lo demás en la variada oferta de los media: desde fotografías de periódicos y revistas hasta el cómic, anuncios publicitarios y etiquetas mercantiles, cajas de empaque, manuales para aprender a bailar y pintar [... (Juanes, 2009, p. 31)

Arthur C. Danto comienza su libro Warhol comentando la obra Antes y después: sueño icónico americano, en donde el artista emblemático del pop art representa el antes y después de una mujer que se opera la nariz. Para ello, tomó del diario, un anuncio de un cirujano plástico que realizaba operaciones estéticas y realizó una pintura exactamente igual al anuncio, pero en formato mayor (201lb, p. 24 y 25).

Curiosamente, esa obra de Warhol puede verse como una metáfora del antes y después en el arte. El antes, el arte moderno; el después, el contemporáneo.

Este texto plantea problemas teóricos que pretenden contestar lo siguiente: ¿fue Andy Warhol quien puso de manifiesto la crisis del "paradigma" de la era del arte e hizo visible una nueva concepción del arte y del artista diferente a la que imperó hasta el arte moderno? ¿por qué se considera lo anterior? Este artículo tiene como objetivo tratar de responder esa cuestión y demostrar que es a partir de Warhol que se genera en el mundo del arte contemporáneo una nueva concepción del arte y del artista como un ente transversal que se mueve entre la cultura de masas y el arte culto y utiliza diferentes disciplinas. Su transversalidad como artista va también en 
el sentido de opuestos que se cruzan: la vida con la muerte, la belleza con el horror.

Warhol además da voz a su época y acota la brecha entre lo ordinario y el arte y entre éste y la realidad, dándole expresión a un mundo que había cambiado no sólo técnicamente, sino que se había vuelto consumista.

También nos podríamos preguntar si fue Warhol el precursor de esta nueva concepción del arte y del artista. Respecto a esto se pretende mostrar las diferencias entre Warhol y Duchamp, quien si bien es rupturista hace su ruptura dentro del propio arte moderno, a diferencia de Warhol.

Si bien, podríamos decir que han sido varios los artistas que han abierto las puertas de la contemporaneidad en el arte, como el propio Marcel Duchamp, quizá nadie lo hizo con la contundencia y la fuerza icónica de Warhol.

Las anteriores preguntas guían mi argumentación y mi planteamiento y el objetivo de este artículo es reflexionar sobre estas cuestiones. Previamente se hará un recorrido breve por algunos antecedentes que nos servirán para darnos el contexto e introducirnos al tema.

\section{DE LAS VANGUARDIAS AL POP ART}

A partir del impresionismo, se sucedieron una serie de vanguardias artísticas que rompían con los postulados de la vanguardia anterior, fijando sus posiciones, casi siempre a través de manifiestos explícitos en donde se contenían los principios rectores del nuevo movimiento. Sin embargo, cada vanguardia se sucedía dentro del mismo relato del arte, cuya abolición comenzaría a ser perceptible a partir de la emergencia del pop art.

Al respecto, Octavio Paz (1990b) señaló que "la oposición a la modernidad opera dentro de la modernidad. Criticarla 
es una de las funciones del espíritu moderno [... El arte moderno es moderno porque es crítico" (pp. 210 y 211). El nobel mexicano va más allá y dice

Cada movimiento artístico negaba al precedente, y a través de cada una de estas negaciones el arte se perpetuaba. Sólo dentro del tiempo lineal la negación podía desplegarse plenamente [.... Hoy somos testigos de otra mutación: el arte moderno comienza a perder sus poderes de negación. Desde hace años sus negaciones son repeticiones rituales: la rebeldía convertida en procedimiento, la crítica en retórica, la transgresión en ceremonia. (p. 211)

Según Peter Gay (1997), especialista en la modernidad artística, ésta tuvo dos rasgos esenciales: el primero fue la atracción por la herejía, es decir, los modernos tenían un espíritu contestatario y rupturista que iba en contra de los cánones académicos heredados de la tradición o del pasado; el segundo rasgo fue la autocrítica o introspección, que se refiere a descubrir los horizontes de la subjetividad, a ser reflexivo, es decir, a desdoblar la conciencia y mirar sobre sí mismo.

\section{EL AGOTAMIENTO DE LAS VANGUARDIAS}

El arte moderno fue a la vez innovador y transgresor, hasta el punto de ensanchar los territorios del arte heredados del pasado y preparar el advenimiento del arte contemporáneo.

Para entender por qué se agotaron las vanguardias y comenzó lo que podríamos definir como un nuevo arte a partir del pop art, es preciso reflexionar cuáles fueron las causas de la extinción de los movimientos de vanguardia.

Las vanguardias llevaron al límite la exploración de la forma, por tanto, había que ir a la idea, terreno en el que fueron pioneros los readymades de Duchamp. Las 
vanguardias exploraron la forma, (desde los experimentos impresio-nistas con la pincelada suelta, pasando por el cubismo, el arte abstracto y el expresionismo); buscando siempre romper con procedimientos inamovibles heredados desde el Renacimiento, tales como la perspectiva lineal, la composición y la figuración. Así, las vanguardias fueron deconstruyendo poco a poco la forma, al punto de llegar a la abstracción absoluta, por ejemplo, en el Cuadrado negro de Malévich. No había nada más que hacer dentro de la forma, así que, había que pasar de lo estético retiniano a lo mental.

De este modo las vanguardias mostraron los límites del arte visual y aurático. Según Walter Benjamin, una obra tiene aura si es original y auténtica (no reproducida técnicamente). Benjamin define al aura como "la manifestación irrepetible de una lejanía" (1989, p. 4); en el caso del arte, una obra que jamás se volverá a repetir.

Ahora bien, era dable pensar que el futuro del arte estaba en la última vanguardia: el expresionismo abstracto; sin embargo, los artistas que lo representaron rendían culto a la abstracción dramática, exteriorizando una realidad interior, además, eran elitistas y ajenos a lo que pasaba en el exterior, en la vida común de la gente común.

Por el contrario, los artistas pop buscaban hacer arte a partir de las convenciones pláticas de los mass media. Personajes como Warhol, surgieron del ámbito del diseño publicitario y por tanto conocían de cerca los nuevos lenguajes de la sociedad del espectáculo y el consumo.

"Los artistas pop hicieron imágenes que cualquiera podía reconocer en una décima de segundo paseando por Broadway: cómics [...] famosos, botellas de coca cola, las grandes cosas modernas que el expresionismo abstracto intentaba ocultar" (Danto, 2011b, p. 79 y 80). 
Para José Jiménez (2010), el pop art "reproduce fielmente el 'lenguaje' simple y directo de los medios, sustituye a la complejidad gestual del expresionismo abstracto, contra el que reacciona. O la complejidad formal y expresiva de las vanguardias históricas" (p. 206).

El arte pop surge entre otras cosas, debido a que después de la Segunda Guerra Mundial hubo un crecimiento de los mercados que generó la incorporación al consumo por parte de las grandes masas. En lo sucesivo el arte tendría que insertarse en un tipo de sociedad en donde la forma mercancía había alcanzado su más amplia extensión social.

"La aparición del arte pop en los países anglosajones, en los inicios de los años sesenta, significa, tras el agotamiento del ciclo de las vanguardias, el comienzo de nuestra verdadera contem-poraneidad artística" (Jiménez, p. 206).

\section{EL FIN DEL ARTE}

Si afirmamos junto con Jiménez, que el arte contemporáneo inicia con el pop art, veamos entonces qué se entiende por tal. Danto menciona que el arte contemporáneo, "no designa un período sino lo que pasa después de terminado un relato legitimador del arte" (2010, p. 36). Ese relato queda comprendido entre el Renacimiento y las vanguardias. Lo que Danto llama el "fin del arte" corresponde al momento en que el arte discurre fuera de una narrativa o de un relato, no significa por tanto que muera el arte o que los pintores dejen de pintar, sino que "la historia del arte, estructurada mediante relatos, había llegado a su fin" (p. 180).

Octavio Paz, mucho antes que Danto, propuso la idea del fin del arte. Lo hizo en 1972 en Los hijos del limo: "No digo 
que vivimos el fin del arte: vivimos el fin de la idea de arte moderno" (1990b, pp. 211). Lo reiteró también en 1990 en su libro La otra voz: "No es el fin del arte: es el fin de la idea de arte moderno. O sea: el fin de la estética fundada en el culto al cambio y la ruptura" (p. 51); es decir, de la estética de la modernidad vanguardista en donde como él mismo lo dijo, lo que imperó al final fue una tradición de la ruptura (p. 50).

\section{ANDY WARHOL Y LA NUEVA CONCEPCIÓN DEL ARTE Y DEL ARTISTA}

Thomas Kuhn en su libro ya clásico La estructura de las revoluciones científicas, propone un esquema de evolución de la ciencia a través de la sucesión de formaciones teóricas dominantes a las que conceptualiza a través de la categoría "paradigma". Por "paradigma" entiende Kuhn "un modelo o patrón aceptado" (2004, p. 51).

Por analogía, podemos pensar el relato del arte a través del establecimiento de paradigmas o formalizaciones relativas a la manera de mirar el arte y conceptualizar sus condiciones tanto de creación como de recepción; de este modo-siguiendo a Belting y a Danto-habría un paradigma anterior a la era del arte, otro que abarcaría la era del arte (del Renacimiento a la modernidad y las vanguardias) y otro que correspondería al fin del arte, período del arte sin relato, o del arte poshistórico o contemporáneo. Asistiríamos de este modo también en el arte a la sustitución de paradigmas. El arte moderno sería desplazado por el arte contemporáneo y este tránsito se pondría de manifiesto a través del advenimiento del pop art y su figura más emblemática: Andy Warhol.

El pop art al plantear lo que Danto llama "la pregunta filosófica del arte" hizo visible la crisis del "paradigma" de la 
era del arte y abrió la puerta al llamado "fin del arte" o arte poshistórico o contemporáneo.

Sólo que este desplazamiento, a diferencia de la cadena evolutiva de los paradigmas de la ciencia de Kuhn, implicaría la disolución misma del relato, la ruptura de toda narrativa en la producción del arte.

Por lo anterior, es posible considerar que el estadounidense Andy Warhol se sitúa en el momento de transición entre el paradigma histórico de la era del arte y la apertura a un estadio de producción entrópica del arte, en el que éste ya no está sujeto a ningún relato legitimador.

La importancia de Andy Warhol y del pop art, estribaría entonces en haber puesto de manifiesto la crisis del "paradigma" de la era del arte, en haber hecho visibles una nueva concepción del arte y del artista.

El arte pop plasma en el terreno artístico la universalización del consumo impuesta por el american way of life: todos, ricos o pobres, podemos consumir lo mismo, por ejemplo, una coca cola.

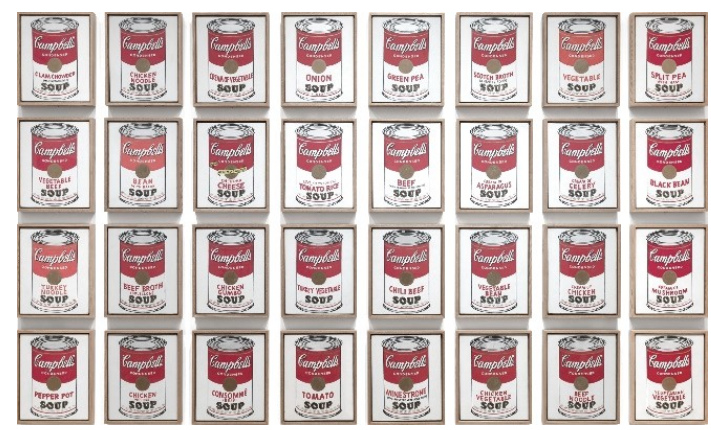

Figura 1. Andy Warhol, Latas de sopa Campbell, 1962, pintura de polímero sintético sobre lienzo, $50.8 \mathrm{~cm}$ x $40.06 \mathrm{~cm}$. MOMA, Nueva York 
Danto, en su libro Andy Warhol, señala: "De repente, la lata de sopa Campbell's, invalidó por ser suficientemente general, todo el canon de la estética filosófica, y al mismo tiempo definió su época" (2011b, p. 59).

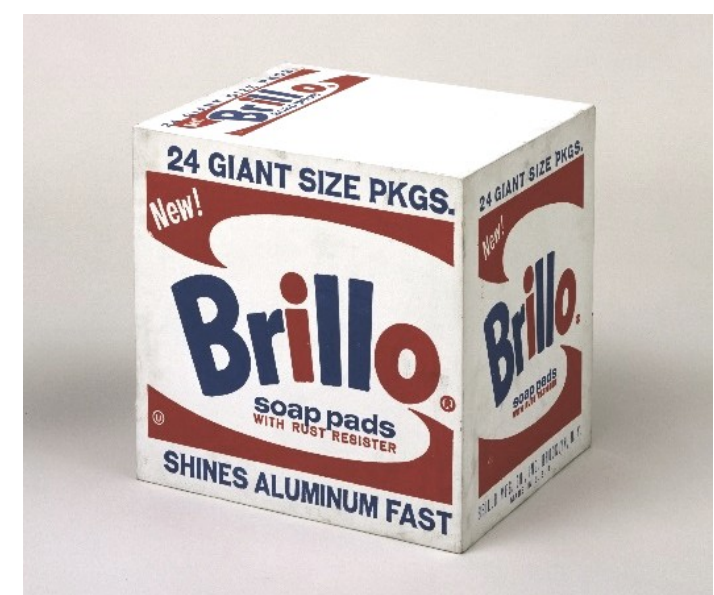

Figura 2. Andy Warhol, Brillo Box, 1964, pintura de polímero sintético y tinta serigrafiada sobre madera, 43.3 x 43.2 x $36.5 \mathrm{~cm}$. MOMA, Nueva York.

La postura de Jorge Juanes es un tanto diferente a la de Danto, sin embargo, también nos ayuda para los fines de este artículo. Para Juanes, Warhol no es el gran filósofo, sino que es un "artista" que se "consagra a descubrir lo singular concreto tras la pantalla aplastante de lo prototípico supraindividual. Lo hace como lo que es, un artista" (2009, p. 46). Lo anterior es una prueba más de que con Warhol surge una nueva concepción del arte y del artista, ya sea desde la posición filosófica referida por Danto, o desde la artística de Juanes. De igual forma, si la Caja Brillo es para Danto un guiño para un público intelectual o una élite, para Juanes el guiño es para las 
masas; pero finalmente en ambos casos, insisto, hay un cambio en la comprensión del arte en relación a la que se tenía antes.

Siguiendo el rastro de Duchamp, el pop art va de la experiencia sensible a la del pensamiento (Danto, 2010, p. 40), de la forma al concepto.

Arthur Danto, en Después del fin del arte, señala que para él cambió la concepción del arte cuando vio la obra Brillo Box de Andy Warhol, pues se asombró al percatarse de que tanto la caja de detergente brillo que estaba en el supermercado, como la elaborada por Warhol, eran idénticas, lo que lo llevó a la pregunta filosófica del arte ¿Qué diferencia hay entre una obra de arte y algo que no lo es, si ambos son iguales? Danto señala que los artistas pop acortaron la brecha entre la realidad y el arte.

La historia del arte, estructurada mediante relatos, había llegado a su fin, ahora lo ordinario se elevaba a nivel de arte. Esa fue la clave del pop art y fue así como modificó también el concepto de arte.

El pop, en resumen "no fue sólo un movimiento que siguió a otro y fue reemplazado por otro. Fue un momento cataclísmico que señaló profundos cambios políticos y sociales y que produjo profundas transformaciones filosóficas en el concepto del arte" (Danto, 2010, p. 188). Es decir, no fue sólo un cambio como el que sucedía de una vanguardia a otra, no fue un cambio de estilo, fue, sin duda, un cambio de paradigma como se ha venido afirmando a lo largo de este texto.

También cambia con Warhol la comprensión del "artista". Andy Warhol se inició en el diseño publicitario, pasó a la pintura, hizo cine, televisión, fundó la Factory, es decir él no era sólo un pintor, o un cineasta, era en el sentido amplio de la palabra "un artista" contemporáneo debido en gran parte a esa transversalidad de actividades o medios. 
"Warhol había expandido el concepto del artista, ahora identificándolo con alguien que ya no limitaba su producto a ningún medio concreto [... Andy reinventó el concepto del artista, otorgándole la libertad de utilizar cualquier medio" (Danto, 201lb, p. 127). El artista entonces se volvió transversal, es decir, mediante el cruce de diversas disciplinas que se tocaban entre sí, como el diseño y la pintura, creaba una nueva forma de hacer arte.

El arte pop fue abiertamente dirigido a las masas mediante la reproducción y multiplicación técnica de las obras. Según Walter Benjamin, "en la época de la reproducción técnica de la obra de arte, lo que se atrofia es el aura de ésta" (1989, p. 3), hecho que hace que el arte pierda "su aquí y ahora" que lo vuelve original. La reproductibilidad técnica de la obra de arte modifica la relación del arte con las masas, pues son éstas las que ahora acceden a la obra de arte y son partícipes de la misma.

El arte se modifica al cambiar la obra que es reproducida y multiplicada técnicamente, pues ya no existe un original, una pieza única. "Warhol se vale, en la mayoría de sus obras de medios técnico-gráficos de reproducción [... La serigrafía le sirve como multiplicador inigualable para realizar-ése es el propósito-ejemplares reproducibles que ponen en crisis la idea de obra única e irrepetible, otrora identificada como 'verdadero arte.'. (Juanes, 2009, p. 33).

$\mathrm{Si}$ en el Renacimiento el artesano al individualizar su creación se convirtió en artista, ahora, con el advenimiento del arte contemporáneo y en particular con Warhol, cambia la noción de artista, según lo menciona Juanes, "negando, en consecuencia, la consagrada identificación del arte con la manualidad" (2009, p. 33).

La nueva comprensión del artista se cristaliza con Warhol, al ser él quien aporte, en palabras de Jorge Juanes, "la otra mirada" (2009, p. 35), es decir, le basta al artista 
cambiar un color o un gesto "para revelar lo que subyace a la presencia abrumadora del mensaje publicitario" (p. 34).

Warhol trató de abolir la distancia entre arte y realidad, por ende, para él cualquier cosa podía ser arte y cualquier persona artista, tal y como lo fue él mismo. "Warhol entendía muy bien el poder de una imagen y su impacto sobre el ciudadano común y corriente su experiencia como diseñador gráfico en revistas de moda, le había enseñado que la publicidad, más que vender mercancías, vendía un estilo de vida: el 'sueño americano'." (Rion, 2017, p. 27). Fue precisamente el cruce de diversas disciplinas como el diseño y la publicidad, con las artes visuales, lo que le permitió a los artistas pop y a Warhol en particular, plasmar y recrear, en el arte y desde el arte, ese american way of life.

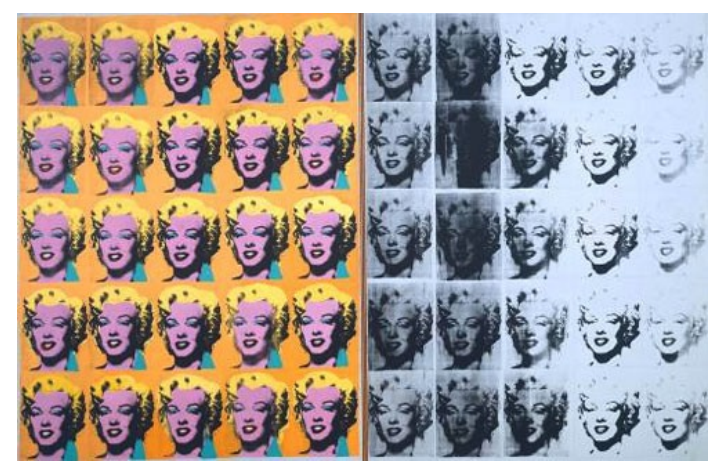

Figura 3. Andy Warhol, Díptico Marilyn, 1962, pintura de polímero sintético y tinta serigráfica sobre lienzo, 2.05 x 1.44 m. Tate, Londres.

Así, por ejemplo, en la obra Díptico de Marilyn o Marilyn dipyich, de 1962. Warhol usó la serigrafía, la fotografía, utilizando el cromatismo de la publicidad y el diseño. Además, utilizó una figura pública, ícono del sueño americano como lo era Marilyn Monroe, pero en 
confluencia entre la fama y lo morboso (Gompertz, 2015, p. 337).

La primera parte del díptico (a color), podría representar la felicidad y la belleza perfecta; Marilyn aparece espectacular y llena de vida. La segunda (blanco y negro), pese a que es la misma imagen, podría representar el precio de la fama, que se deslava y por el cual se pierde el gusto por vivir. Marilyn aparece deteriorada, como una mujer que ha perdido el glamour y que es frágil. Esta dialéctica aparece también en otras obras en las que plasma situaciones variadas que transitan de la vida a la muerte, como "las imágenes de las celebridades [que] fueron producidas el mismo tiempo que sus fotografías de suicidios, accidentes automovilísticos y otros desastres" (Fogle, 2017, p. 5). Es decir, su transversalidad como artista va también en el sentido de opuestos que se cruzan: la vida con la muerte, la belleza con el horror, lo sagrado con lo profano, lo temporal con lo atemporal.

En Warhol hay otra forma de transversalidad de gran importancia: aquella que se expresa como un franco encuentro entre la cultura de masas y el arte culto. Andy Warhol fue el artista que mejor supo personificar artísticamente una época de cambio social, como fue la de los sesenta; le dio expresión a una forma de arte en correspondencia con una sociedad que por sí misma ya era pop (la sociedad del espectáculo, la de la estetización de la mercancía); tomó en serio las convenciones plásticas de la publicidad, del diseño y de los medios de comunicación de masas, del star sustem, y mediante una transfiguración creativa las convirtió en gran arte. En fin, el hombre de la peluca platino, le dio expresión plástica a un mundo en donde se habían cambiado los roles generacionales, donde la sociedad autoritaria daba paso a una sociedad permisiva, glamourosa y consumista. 
Han sido varios los artistas que han abierto las puertas al arte contemporáneo, como el propio Marcel Duchamp, pero quizá nadie lo hizo con la garra del artista del pop art.

\section{El URINARIO VS. LA CAJA BRILLO}

La primera pregunta que se nos viene a la cabeza es pensar: ¿y por qué Warhol y no Duchamp, es el que rompe el paradigma del arte? Lo cierto es que el dadaísta rompe dentro del mismo código canónico vanguardista, no aplicando lo dicho por Thomas Kuhn en el sentido de que se sustituya un modelo por otro.

Si para Thomas Kuhn, un paradigma es un modelo o patrón aceptado (2004, p. 51), hemos de pensar que Duchamp hizo su ruptura (al igual que cada artista vanguardista), dentro del modelo del arte moderno, es decir, dentro de un canon, de un patrón o de un relato ya establecido cuya tradición era "romper" con la tradición.

Efectivamente, podríamos citar a Duchamp como el primer artista conceptual que pasó de la forma a la idea, o como aquél, que transfiguró el lugar común y lo convirtió en arte; sin embargo, insisto, lo hizo dentro de un movimiento vanguardista. Claro que fue rupturista, claro que con él cambió la forma de ver el arte, algo parecido sucedió con Picasso o con Kandinsky: todos se inscribían en un canon propio de la modernidad.

Ahora bien, si tomamos al arte moderno como un paradigma en el cual se compartían rasgos comunes, podemos pensar que con el arte contemporáneo se declara invalido el paradigma anterior y nace uno nuevo y es precisamente Warhol un punto clave en este rompimiento.

Me explico un poco más: los movimientos del arte moderno, como el dadaísmo, en el que militó Duchamp, tenían, como se dijo anteriormente, algunas características

$$
\text { C A L E I D O }
$$


comunes, entre las cuales estaba, por ejemplo, la de la ruptura de la tradición, o sea, el romper con el movimiento artístico anterior. Incluso Octavio Paz dijo irónicamente que esa ruptura y esa rebeldía propia de la modernidad, paradójicamente se habían vuelto una tradición: "La tradición moderna es la tradición de la ruptura, una tradi-ción que se niega a sí misma y que se perpetúa" (1990a, pp. 50 y 51).

Esta tradición rupturista se convirtió en un canon propio del arte moderno dentro de cuyo relato se circunscribe Marcel Duchamp. El caso de Warhol es diferente. Primero, no transitó dentro de ninguna vanguardia. Segundo, no buscó romper la tradición.

En Duchamp, como en cualquier auténtico vanguardista, hay un espíritu de ruptura con el pasado, de contestación, de provocación a un mundo burgués que es propio de un espacio moderno. Tiene un gesto dadaísta, se burla incluso: "la traducción de la obra de arte en el readymade por parte de Duchamp-en último término una burla patética de una obra de arte y del acto creativo-es la afirmación definitiva de su pesimismo nihilista" (Kuspit, 2012, p. 30). En Warhol es menos claro lo anterior pues no existe el espíritu de confrontación, por el contrario, el artista norteamericano parece acomodarse a la funcionalidad del entorno en el que vive: el nuevo capitalismo, la sociedad del consumismo y del espectáculo.

La fascinación de Warhol por las convenciones estéticas del mundo consumista y la publicidad no aparecen en Duchamp, ya que éste parte de la actitud vanguardista de dinamitar la academia y los museos (y la sociedad burguesa misma). En Warhol hay fascinación por lo popular, en Duchamp hay crítica contra el establishment, mismo que el norteamericano venera. De aquí no debemos colegir la ausencia de un espíritu transgresor en Warhol presente en 
él como en todo gran artista. Su transgresión tiene que ver más con códigos estéticos, que, con posicionamientos explícitamente políticos o ideológicos, aunque desde luego las implicaciones de esta naturaleza se dan de una forma $u$ otra en sus obras.

Warhol no hace un arte discursivo, ni explícitamente político ni con un posicionamiento frente al pasado o frente a la sociedad, características más propias del espíritu moderno que del contemporáneo.

El pop fue "un arte intensamente 'desideologizado'. No sólo asume la indiferenciación formal, sino que rechaza la idea de la responsabilidad moral del arte" (Jiménez, 2010, p. 212). Warhol es un ejemplo de lo anterior.

José Jiménez dice que si se pudiera elegir la obra "más significativa" del pop art, sería la lata de sopa Campbell, por la forma en que "hace patente la tendencia a la nivelación, a la indistinción de la imagen, convertida en elemento de consumo masivo" (2010, pp. 212 y 213).

A diferencia de Duchamp, Warhol no se dirige a los intelectuales, sino "al ciudadano estadounidense común y corriente" (Juanes, 2009, p. 36), es decir, no busca intelectualizar su arte como probablemente lo hizo Duchamp, lo cual inferimos en la siguiente aclaración que hizo el francés sobre el rechazo del Urinario o la Fuente en una exposición: "Si el señor Mutt hizo o no la fuente con sus propias manos carece de importancia. Él la eligió. Cogió un artículo ordinario de la vida y lo colocó de tal manera que su significado habitual despareció bajo nuevo título y punto de vista-creó un nuevo pensamiento para ese objeto" (Juanes, 2002, pp. 55 y 56). Parece que el propio Duchamp hablara de la transfiguración del lugar común, como lo hizo Danto respecto a la obra de Warhol, sin embargo, recalco, hay una diferencia de intención: Duchamp intentaba racionalizar esa transfiguración, "provocar al establishment" 
(Gompertz, 2015, p. 262). Por el contrario, Warhol, no buscaba eso, quería simplemente desaparecer la brecha entre arte y vida, esa vida capitalista norteamericana consumista y estetizada mercantilmente.

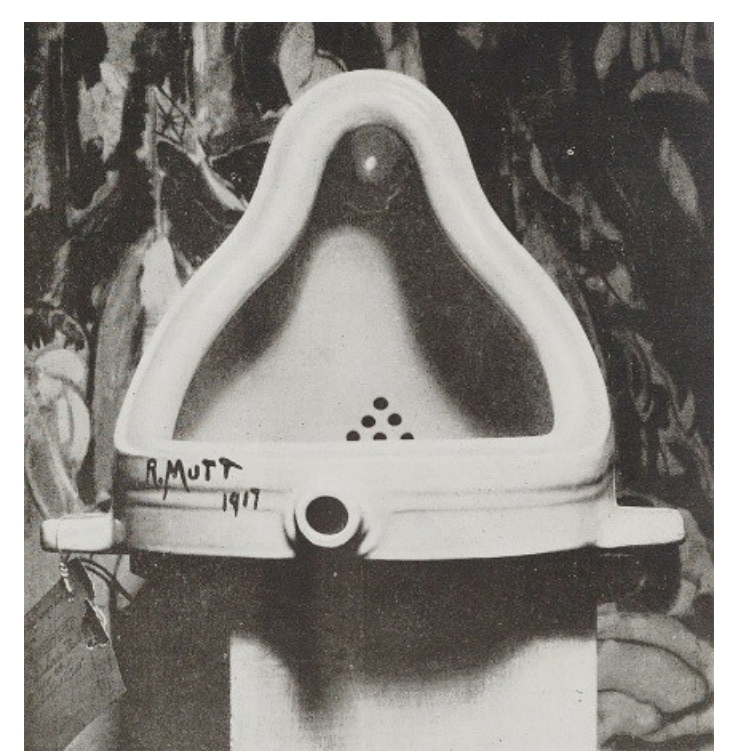

Figura 4. Marcel Duchamp, la Fuente o el Urinario, 1917. Fotografía de Alfred Stieglitz.

Lo anterior no implica que Warhol no tuviera la intención de que el gran público común y corriente tomara conciencia de algunas situaciones; por el contrario, tomemos como ejemplo sus obras sobre desastres, disturbios, condenados a muerte en la silla eléctrica, accidentes y muerte; en éstas busca "desentrañar la parte negra de la modernidad estadounidense" (Juanes, 2002, p. 39).

La diferencia entre Warhol y Duchamp o bien, entre la Brillo Box del primero y los ready-mades del segundo, fue que "nada de lo que hizo Duchamp celebró lo ordinario. Tal vez 
debilitaba la estética y desafiaba las fronteras del arte." (Danto, 2010, p. 188), pero no celebraba las conven-ciones plásticas de la publicidad y de la comunicación de masas, como lo hacía el arte pop.

Para Danto la obra más significativa del arte pop, es la Brillo Box, a través de la cual explica su teoría de la transfiguración del lugar común.

Warhol toma las cosas ordinarias de la gente ordinaria para hacer una propuesta artística; al hacerlo, deja sin sentido la distinción entre arte elevado y popular, que aún existía en las vanguardias. Duchamp, por su parte, estableció esa frontera.

Jiménez coincide con lo anterior, al establecer que "los artistas pop introdujeron como idea la indistinción de los objetos de la cultura de masas y los productos artísticos, dando así un paso más respecto a Duchamp, que siempre mantuvo la diferencia entre obras de arte y ready mades" (2010, p. 212).

Si Duchamp hizo la "proclamación de la muerte de la pintura" (Juanes, 2010, p. 201) y de lo lo retiniano, Warhol fue un artista transversal que utilizó no sólo los recursos de la pintura (para él vigente) o de las artes gráficas como la serigrafía o el grabado, además incorporó diferentes disciplinas a su arte.

Warhol fue un artista más lúdico que contestatario, más propenso a la hibridación propia de la posmodernidad, que a las ideologías.

Para Donald Kuspit (2012, p. 27), Duchamp quería diferenciar el arte del no arte. Por ejemplo, el Urinario como readymade es arte y no arte a la vez, ya que es un objeto que tiene doble identidad. Es "arte" pues es mentalmente arte (por la psiqué del autor que lo convierte en tal), pero a la vez es "no arte" ya que físicamente no es arte. El objeto 
se vuelve arte por el acto creativo, por la intención del artista.

Para Duchamp el acto creativo pasa de la intención a la realización y esa "diferencia entre lo que tenía intención de realizar y lo que de hecho realizó es el 'coeficiente artístico' personal contenido en la obra" (2010, p. 66).

Marcel Duchamp, para Joseph Kosuth (El arte después de la filosofía, 1969), fue el primero que se cuestionó sobre la naturaleza del arte, otorgándole así una identidad propia [doble, diría Kuspit]. A partir del creador de los ready mades, según Kosuth se dio inicio al arte conceptual.

La diferencia con Warhol es que éste no hace esta reflexión, esta diferenciación, entre arte y no arte.

\section{CONCLUSIONES}

Warhol fue un artista que impuso un nuevo modelo tanto del arte como del artista.

Podríamos decir que Andy Warhol desplazó el paradigma del arte moderno, acortó la distancia entre arte y vida y volvió invisible para el ojo aquello que hace arte al arte; asimismo dio voz a su época y elevó lo ordinario a nivel del arte.

Respecto al nuevo paradigma del artista que encarnó Warhol, podemos decir que es transversal porque se mueve entre la cultura de masas y el arte culto, además hace un cruce de diversas disciplinas para producir su arte y en cuanto a su temática, va desde el glamour de las estrellas, hasta la violencia social, racial y de estado.

También, como artista personificó una época, convirtiéndose él mismo y su figura en una encarnación de una nueva cultura y de una nueva sociedad.

Warhol no rompe con la pintura, como Duchamp lo hizo (dentro del relato legitimador del arte moderno a que se 
refiere Danto, 20lla); por el contrario, todo lo toma y todo lo integra. De ahí su transversalidad como artista. Warhol le debe al diseño gráfico, a la publicidad, a Duchamp, a la pintura y a su tiempo. Eso lo diferencia de los vanguardistas. Warhol no reniega del pasado, sino que lo asume y así hace su arte.

Finalmente, el pop art marcó el fin del gran relato occidental en cuanto al arte, pues ya no fue la continuación de arte anterior, sino que fue el punto de partida para el surgimiento de un territorio artístico, entrópico, abierto y abigarrado, al que hoy damos el nombre de arte contemporáneo.

El gran mérito de Warhol fue desdibujar la frontera que siempre hubo entre el arte y la vida. Todo puede ser arte, todos podemos ser artistas. Ese es su legado.

\section{REFERENCIAS}

Benjamin, W. (1989). La obra de arte en la época de su reproductibilidad técnica. En W. Benjamin, Discursos ininterrumpidos I. Buenos Aires: Taurus.

Danto, A. C. (2010). Después del fin del arte. El arte contemporáneo y el linde de la historia. Barcelona: Paidós.

Danto, A. C. (20lla). La transfiguración del lugar común. Una filosofía del arte. Barcelona: Paidós.

Danto, A. C. (2011b). Andy Warhol. Barcelona: Paidós.

Duchamp, M. (2010). El acto creativo. En M. Duchamp, Cartas sobre el arte 1916-1956. Barcelona: Elba

Gay, P. (1997). Modernidad. La atracción de la herejía. De Baudelaire a Beckett. Barcelona: Paidós.

Fogle, D. (2017). Andy Warhol: Estrella oscura. En K. Brummel y D. Fogle (Eds.), Andy Warhol: estrella oscura |Catálogo de exposición]. Ciudad de México: Museo Jumex. 
Gompertz, W. (2015). ¿Quée estás mirando? 150 años de arte moderno en un abrir y cerrar de ojos. México, D.F: Taurus. Kuhn, T.S. (2004). La estructura de las revoluciones cientificas.

México, D.F: Fondo de Cultura Económica.

Kosuth, J. (1969). El arte después de la filosofía.

Kuspit, D. (2012). El fin del arte. Madrid: Akal.

Juanes, J. (2002). Más allá del arte conceptual. México, D.F:

CONCAULTA.

Juanes, J. (2009). Pop art y la sociedad del espectáculo. México, D.F: UNAM.

Juanes, J. (2010). Territorios del Arte contemporáneo. México, D.F.: Ítaca.

Jiménez, J. (2010). Teoría del arte. Madrid: Editorial Tecnos.

Paz, O. (1990). La otra voz. Poesía y fin de siglo. México, D.F.: Seix Barral.

Paz, O. (1990). Los hijos del limo. Del romanticismo a la vanguardia. México, D.F: Fondo de Cultura Económica.

Rion, I. (2017). Éramos famosos, y no existia nada que pudiera derrocarnos. No existía nada que pudiera derrocarnos porque éramos famosos. En K. Brummel y D. Fogle (Eds.), Andy Warhol: estrella oscura |Catálogo de exposición]. Ciudad de México: Museo Jumex.

\section{ACERCA DE LA AUTORA}

Patricia Aurora Ortiz Lozano (mondayblue72@hotmail.com) es maestra en Arte por la UAA. Estudió también la Maestría en Arte contemporáneo en la Universidad de las Artes. Es docente y autora de 5 libros de poesía. Ha sido becaria del FONCA y ponente en el Congreso Internacional de Literatura Comparada en Harvard (ORCID 0000-0003-4120-8695). 
Recibido: 08/01/2019

Aceptado: 25/03/2019

CÓMO CITAR ESTE ARTÍCULO

Ortiz Lozano, P. A. (2020). Una nueva concepción del arte y del artista en el arte contemporáneo. Caleidoscopio - Revista Semestral de Ciencias Sociales y Humanidades, 23(42). 125-147.

doi: $10.33064 / 42 \operatorname{crscsh} 2155$ 